\title{
Análisis de la Calidad de leche producida por ganaderos rurales en la parroquia Pastocalle Cotopaxi y su influencia en la economía del sector.
}

Análisis de la Calidad de leche producida por ganaderos rurales en la parroquia Pastocalle Cotopaxi y su influencia en la economía del sector.

Edgar Vinicio Pallango Fernandez. ${ }^{1}$, Mónica Alexandra Moreno Barriga. ${ }^{2}$, Andres Joao Noguera Cundar. ${ }^{3}$. Fabián Marcelo Moreno Barriga. ${ }^{4} \&$ Sayuri Monserrath Bonilla Novillo. 5

Recibido: 28-02-2019 / Revisado: 29-02-209 /Aceptado: 24-03-2019/ Publicado: 05-04-2019

\begin{abstract}
.
DOI: https://doi.org/10.33262/cienciadigital.v3i2.450

The objective of this research is to conduct a study of the quality of milk that is produced by farmers producing peasants of the Pastocalle parish of Cotopaxi province and its economic development, the producers and milk processing plants located in the area are studied, in this way the problem is recognized that the inhabitants of this parish have and that they dedicate themselves to this activity being the same their main source of income. Interviews and interviews are then used with the groups involved to determine the quality of the product, that is, how the producers perceive the quality of their own product and how the harvesting plants evaluate the quality and its lache, in this way it is possible to recognize the problematic that the inhabitants of this parish who are dedicated to this activity live, finding that the quality of good and regular milk predominates in front of the requirements of the receiving and processing plants of the sector that demand a raw material of excellent quality, on the other hand it is important

1 Universidad Tecnológica Indoamérica, Maestría en Gestión de Proyectos, Ambato, Ecuador. vpf-vinicio.pallango@hotmail.es

2 Escuela Superior Politécnica de Chimborazo, Facultad de Mecánica. Riobamba, Ecuador. moreno@espoch.edu.ec

3 Escuela Superior Politécnica de Chimborazo, Facultad de Mecánica. Riobamba, Ecuador. andres.noguera@espoch.edu.ec

4 Escuela Superior Politécnica de Chimborazo, Facultad de Recursos Naturales. Riobamba, Ecuador. fabian.moreno@espoch.edu.ec

5 Escuela Superior Politécnica de Chimborazo, Facultad de Administración de Empresas. Riobamba, Ecuador. smbonilla@espoch.edu.ec
\end{abstract}


to take in account that the Ecuadorian legislation has regulated the payment of milk for quality points in function of which the farmers that produce high quality will receive good prices and therefore high profitability thus improving their income to subsist with a better standard of living.

Keywords: Quality, Economy, Milk, Requeriments, Raw Material .

\section{Resumen.}

El objetivo de esta investigación es realizar un estudio de la calidad de leche que se produce por los ganaderos campesinos productores de la parroquia Pastocalle provincia de Cotopaxi y su incidencia económica, se estudia a los productores y plantas procesadoras de leche ubicadas en la zona, de esta forma se reconoce el problema que tienen los habitantes de esta parroquia y que se dedican a esta actividad siendo la misma su principal fuente de ingresos. Se utiliza entonces entrevistas y encuestas a los grupos implicados para determinar la calidad de la materia prima, es decir como perciben los productores la calidad de su propio producto y como las plantas recolectoras evalúan la leche y su calidad, de esta forma se logra reconocer la problemática que viven los habitantes de esta parroquia que se dedican a esta actividad, encontrándose que predomina la calidad de leche buena y regular frente a los requerimientos de las plantas receptoras y procesadoras del sector que exigen una materia prima de excelente calidad, por otro lado es importante tomar en cuenta que en la legislación ecuatoriana se ha normado el pago de leche por puntos de calidad en función de lo cual los ganaderos que producen alta calidad recibirán buenos precios y por ende alta rentabilidad mejorando así sus ingresos para subsistir con un mejor nivel de vida.

Palabras claves: Calidad, Economía, Leche, Ingresos, Materia Prima.

\section{Introducción.}

Con respecto a los sistemas de producción de leche, es necesario indicar que se pueden encontrar tres sistemas de producción de leche: el intensivo, el familiar y el doble propósito, enfocamos entonces el estudio en el sistema "familiar", pues es el más frecuente, aportando un elevado porcentaje de la leche fresca que consume en el país, ademas de ser una comunidad la cual esta bajo análisis en esta investigación. Luego es importante señalar que el sistema familiar se mantiene vigente y ha sobrevivido por la elevada utilización de mano de obra de los integrantes de la familia, además de que el ordeño se realiza en forma manual, sin embargo como resultado de estos factores aparecen problemas relacionados con deficiencias de control sanitario y de calidad, falta de acceso a capacitación especializada, créditos y otros servicios importantes en general, además que los canales de comercialización de éstos productores son: venta directa de leche cruda al consumidor y venta a acopiadores de leche. 
Para combatir estas deficiencias de control sanitario de la leche, al utilizar el sistema familiar es importante aplicar un concepto conocido como: buenas prácticas de producción pecuaria (BPP), entre las cuales se pueden mencionar, mejorar las condiciones y manejo de las vacas antes del ordeño, durante el ordeño y en el post-ordeño; conservar la leche de la mejor manera posible; monitorear constantemente la calidad de la leche; limpiar y desinfectar de manera correcta cualquier equipo y utensilio utilizado. Estas prácticas de higiene básicas son medidas necesarias y de carácter preventivas, que aplicadas a las instalaciones, a las fases de ordeño, al manejo de las vacas, limpieza, desinfección y conservación de la leche, reducirán significativamente el riesgo de contaminación de la leche cruda por microorganismos, sustancias químicas y materiales extraños con ello se protege de contaminaciones a los procesadores y consumidores, y además se crea una cultura de higiene en los ganaderos para ofrecer un producto de calidad.

Entonces al obtener y ofrecer un producto de calidad, esto permite identificar que "Una leche de buena calidad es más fácil de trabajar y genera un mejor rendimiento, razón por la cual puede pagarse mejor al productor". De esta forma en nuestro país durante el transcurso de los últimos años se ha trabajado arduamente en lograr un pago de la leche por su calidad, es decir que se busca beneficiar la producción de leche de buena calidad, entonces se concluye que un mejor rendimiento producirá mejor rentabilidad en la actividad de producción lechera, recalcando que la calidad de leche influye en el precio y por ende en los ingresos de los ganaderos lecheros.

En nuestro país por ejemplo el costo promedio de producción del litro de leche a nivel de finca cuando el método de producción es familiar y desarrollado por pequeños ganaderos, oscila entre \$. 0,32 y \$. 0,36 en comparación a la leche de excelente calidad que alcanza valores de \$. 0,50 e incluso más en las plantas procesadoras que aplican el pago por calidad., estos valores se han determinado mediante mutuos acuerdos entre el ganadero productor y el comprador directo, que normalmente es el industrial de las plantas lecheras.

Con estas premisas es fácilmente reconocible la relación estrecha existente entre la calidad del producto, y los beneficios económicos que pueden resultar sobre los productores.

\section{Metodología}

La perspectiva utilizada en este trabajo de tipo cualitativa y cuantitativa. Cualitativa porque se profundiza y analiza el proceso y cadena de producción de la leche, estudiando la calidad y rentabilidad de los ganaderos de Pastocalle. Se realiza una metodología Cuantitativa porque toma en cuenta una realidad repetible cuantificándola permitiendo analizar los datos inherentes a la calidad de la leche y rentabilidad obtenida de forma numérica, buscando las causas de los hechos, aplicando mediciones cuantitativas para valorizar los impactos de el problema en estudio. 
De esta manera el presente ensayo, utiliza una modalidad de estudio de campo pues es necesario trasladarse al lugar de ocurrencia de los hechos para realizar la investigación de manera sistemática. Se toma contacto de manera directa con la realidad y con la comunidad de Pastocalle para la obtención de información inherente al objetivo de este estudio.

Ahora se indica la muestra a la cual se realiza el análisis de este trabajo, existen 11449 habitantes en la parroquia Pastocalle, en donde la ganadería es desarrollada como actividad regular por los habitantes a partir de los 15 años hasta los 64 años de edad, en este intervalo de edad se encuentran 6.641 habitantes de los cuales el 48 por ciento se dedican a la ganadería lechera, siendo entonces 3.188 personas las que se encuentran directamente dedicadas a esta actividad y constituyen la población universo de investigación.

Sobre esta población se trabaja sistemáticamente tomando en cuenta los siguientes aspectos:

- Identificar el universo de investigación.

- Selección de las técnicas a emplear en el proceso de recolección de información (encuesta, entrevista, observación, etc.).

- Seleccionar los instrumentos de acuerdo a cada técnica.

- Planificar cronométricamente la ejecución de las técnicas seleccionadas.

- Aplicar las encuestas y entrevistas en función de la planificación.

Finalmente para el procesamiento y análisis de la información se utilizará una tabla simple, compuesta por filas y columnas donde se muestra la alternativa, frecuencia, porcentaje y total; para la visualización de datos el tipo de gráfico circular, por ser el adecuado para representar conjuntos de pares, muy claro para establecer comparación simple y porcentajes; posteriormente se hará un análisis conciso y por último la interpretación concreta de los datos obtenidos con los instrumentos utilizados.

\section{Resultados}

\section{Encuesta productores}

En esta sección se muestran en primer lugar los resultados obtenidos respecto a las encuestas realizadas y se analizan los resultados de cada una de las preguntas, el cuestionario ha sido aplicado in situ a los ganaderos del sector, específicamente a una muestra representativa formada por 356 personas dedicadas a la actividad agrícola ganadera cuya producción es generalmente entregada a los recolectores informales de leche denominados "piqueros" que son intermediarios que normalmente se llevan la mayor parte de rentabilidad.

La primera pregunta manifiesta: ¿Qué recursos emplea para producir leche? De donde se obtienen los siguientes datos: 
Tabla 1. Recursos utilizados para producir leche.

\begin{tabular}{lll}
\hline Alternativas & Frecuencia & Porcentaje \\
\hline Económicos & 109 & $31 \%$ \\
Humanos & 43 & $12 \%$ \\
Naturales & 37 & $10 \%$ \\
Todos los anteriores & 167 & $47 \%$ \\
TOTAL & 356 & $100 \%$ \\
\hline
\end{tabular}

Fuente: Los autores

Esta tabla permite identificar varios aspectos importantes, por ejemplo, que el $47 \%$ de los productores campesinos de la parroquia, tienen conciencia de que para producir leche se emplean todos sus recursos disponibles, es decir dinero propio o ajeno, mano de obra familiar o contratada, así como terrenos, agua, pastos, etc. En función de éstos recursos invertidos y de los beneficios obtenidos tienen noción de la rentabilidad económica que están recibiendo en esta actividad. Un porcentaje correspondiente a la tercera parte de los ganaderos da mayor relevancia a los recursos económicos que se invierte en la producción lechera. El 78\% de productores toma muy en cuenta el dinero que se invierte en la actividad de producir leche. Menos del 12\% de ganaderos dan relevancia a la utilización de recursos humanos y naturales seguramente porque la mano de obra es propia y poseen terrenos y pastos para el ganado.

La siguiente pregunta es: ¿Considera usted que la actividad lechera es rentable?

Tabla 2. Rentabilidad de la actividad lechera.

\begin{tabular}{lll}
\hline Alternativas & Frecuencia & Porcentaje \\
\hline Siempre & 23 & $7 \%$ \\
Frecuentemente & 182 & $51 \%$ \\
A veces & 139 & $39 \%$ \\
Nunca & 12 & $3 \%$ \\
TOTAL & 356 & $100 \%$ \\
\hline
\end{tabular}

Fuente: Los autores. 
Con estos datos se nota que para un poco más de la mitad de los ganaderos encuestados la actividad lechera "frecuentemente" es rentable, es decir en algunas ocasiones esporádicas no lo es seguramente por temas de calidad entre otros factores. Para un porcentaje del $40 \%$ la actividad de producir leche tan solo "a veces" es rentable lo cual indica que con frecuencia experimentan pérdidas económicas, sin embargo, para el 7\% de productores encuestados la actividad lechera "siempre" es rentable, es decir el pago recibido por su producto satisface sus expectativas y necesidades, pero también existe el 3\% de ganaderos que indican que para ellos la actividad de producir leche "nunca" es rentable. Todo esto permite deducir que, mientras mayor volumen de producción, mayor rentabilidad, siempre y cuando el producto cumpla las normativas y exigencias de calidad.

La pregunta a continuación indica por su parte: ¿Cuál es el porcentaje de recursos propios que utiliza para producir leche?

Tabla 3. Recursos propios utilizados para producir leche.

\begin{tabular}{lll}
\hline Alternativas & Frecuencia & Porcentaje \\
\hline Del 1\% al 25\% & 16 & $4 \%$ \\
Del 25\% al 50\% & 28 & $8 \%$ \\
Del 50\% al 75\% & 69 & $19 \%$ \\
Del 75\% al 100\% & 243 & $68 \%$ \\
TOTAL & 356 & $100 \%$ \\
\hline
\end{tabular}

Fuente: Los autores

Estos resultados indican que un porcentaje considerable de ganaderos (68\%) desarrollan la actividad lechera con recursos prácticamente propios esto indica que no tienen acceso a créditos o temen el endeudamiento lo cual limita su volumen de producción. Aproximadamente la quinta parte de los ganaderos encuestados (19\%) utilizan más de la mitad hasta las tres cuartas partes de sus recursos propios para producir leche lo cual demuestra que si hacen uso de algún tipo de financiamiento de terceros. Un porcentaje pequeño del $8 \%$ produce utilizando recursos ajenos o financiados desde $50 \%$ a $75 \%$. Y como observación final se aprecia que existe un mínimo de ganaderos que financia su actividad con recursos de terceros casi en su totalidad para producir leche. Estos datos nos indican que prácticamente las tres cuartas partes de los ganaderos encuestados utilizan preferentemente recursos propios.

El siguiente punto de análisis indica: ¿Cuál es el porcentaje de la actividad lechera en su economía? 
Tabla 4. Porcentaje de la actividad lechera en la economía de los ganaderos.

\begin{tabular}{lll}
\hline Alternativas & Frecuencia & Porcentaje \\
\hline Del 1\% al 25\% & 21 & $6 \%$ \\
Del 25\% al 50\% & 83 & $23 \%$ \\
Del 50\% al 75\% & 152 & $43 \%$ \\
Del 75\% al 100\% & 100 & $28 \%$ \\
TOTAL & 356 & $100 \%$
\end{tabular}

\section{Fuente: Los autores}

Para casi la mitad de los ganaderos la actividad lechera constituye de la mitad hasta las tres cuartas partes de su economía familiar, es decir que parte considerable de sus actividades e ingresos son relacionados con la producción de leche. En cambio, para un tercio de los productores, aproximadamente, la actividad lechera es muy importante, ya que influye del $75 \%$ hasta el $100 \%$, esto indica que esta porción de campesinos vive prácticamente de esta actividad. Para el 23\% la actividad lechera representa desde la cuarta parte hasta la mitad de su economía o ingresos familiares. Por otro lado, para un porcentaje bajo de los ganaderos, correspondiente al 6\%, la actividad productora de leche no supera la cuarta parte de la economía familiar, lo que indica que estos campesinos se dedican a otras actividades económicas para generar ingresos.

Para continuar con el análisis se realiza la pregunta: ¿Considera Ud. que el esfuerzo de producir leche está de acuerdo con la rentabilidad que recibe?

Tabla 5. Esfuerzo empleado para producir leche respecto con la rentabiliad recibida.

\begin{tabular}{lll}
\hline Alternativas & Frecuencia & Porcentaje \\
\hline Siempre & 61 & $17 \%$ \\
Frecuentemente & 197 & $55 \%$ \\
A veces & 74 & $21 \%$ \\
Nunca & 24 & $7 \%$ \\
TOTAL & 356 & $100 \%$ \\
\hline
\end{tabular}

Fuente: Los autores 
Si bien más de la mitad de ganaderos considera que "con frecuencia" el esfuerzo de producir leche está de acuerdo con la rentabilidad que recibe, se evidencia también que a veces no se cumple esta condición para este grupo de ganaderos. La quinta parte de productores dice que "a veces" el esfuerzo de producir leche está de acuerdo con la rentabilidad que recibe lo que indica que los recursos empleados arrojan ingresos que no satisfacen las expectativas, sin embargo un poco menos de la quinta parte de productores están satisfechos con la rentabilidad recibida por su esfuerzo en la actividad lechera al considerar que siempre reciben buena rentabilidad, pero también existe un mínimo porcentaje que afirma no tener nunca rentabilidad por tanto siempre está perdiendo al producir leche. Es importante mencionar que los ganaderos campesinos encuestados son pequeños productores que realizan su actividad de manera tradicional.

La siguiente pregunta se refiere a la calidad del producto en análisis: ¿Qué calidad de leche considera Ud. que produce?

Tabla 6. Calidad de leche producida.

\begin{tabular}{lll}
\hline Alternativas & Frecuencia & Porcentaje \\
\hline Excelente & 39 & $11 \%$ \\
Buena & 204 & $57 \%$ \\
Regular & 113 & $32 \%$ \\
Mala & 0 & $0 \%$ \\
TOTAL & 356 & $100 \%$ \\
\hline
\end{tabular}

Fuente: Los autores

Más de la mitad de productores tiene la convicción que la leche que produce es de buena calidad, sin embargo, tan sólo la décima parte de los ganaderos encuestados afirma que el producto que produce es de excelente calidad, un porcentaje significativo correspondiente a la tercera parte de ganaderos admite que la leche que produce es de calidad regular, nadie admite o indica que su producción es de mala calidad.

Continuando con el estudio tenemos: ¿Ha experimentado pérdidas económicas en la actividad lechera este último año? 
Tabla 7. Pérdidas económicas en la actividad lechera en el último año.

\begin{tabular}{lll}
\hline Alternativas & Frecuencia & Porcentaje \\
\hline Siempre & 15 & $4 \%$ \\
Frecuentemente & 162 & $46 \%$ \\
A veces & 152 & $43 \%$ \\
Nunca & 27 & $8 \%$ \\
TOTAL & 356 & $100 \%$ \\
\hline
\end{tabular}

\section{Fuente: Los autores}

El $89 \%$ de ganaderos encuestados ha experimentado con frecuencia o a veces pérdidas económicas este último año en la actividad lechera, tan sólo el $8 \%$ no lo ha experimentado. Las pérdidas económicas básicamente están relacionadas con rechazos del producto en las plantas procesadoras por mala calidad, a esto se suma la baja producción de los pequeños ganaderos cuya actividad la realizan de manera convencional o tradicional. Las pérdidas económicas afectan directamente la rentabilidad de los productores que cada vez buscan otras alternativas para generar ingresos para subsistir sin antes haber optado por mejorar su calidad y productividad.

Se analiza a continuación la pregunta: ¿Con qué frecuencia le han rechazado leche por mala calidad?

Tabla 8. Frecuencia de rechazo de leche por mala calidad.

\begin{tabular}{lll}
\hline Alternativas & Frecuencia & Porcentaje \\
\hline Siempre & 19 & $5 \%$ \\
Frecuentemente & 133 & $37 \%$ \\
A veces & 159 & $45 \%$ \\
Nunca & 45 & $5 \%$ \\
TOTAL & 356 & $100 \%$
\end{tabular}

Fuente: Los autores 
El rechazo de leche por temas de mala calidad por parte de las plantas procesadoras afecta a la mayor parte de productores de todo el país. Según entrevistas realizadas a los encargados de calidad de las principales plantas lecheras del sector como Alpina y Parmalat donde la leche de Pastocalle llega, la alta acidez, alto contenido bacteriano y presencia de antibióticos son los principales motivos por los que se rechaza la leche. El 82\% de los ganaderos investigados afirman que a veces y frecuentemente su producto ha tenido problemas de calidad por lo que las plantas lo han rechazado sin ningún tipo de indemnización.

Como punto final de análisis se encuentra la pregunta: ¿Qué rentabilidad considera Ud. que le genera la actividad lechera?

Tabla 9. Rentabilidad en la actividad lechera.

\begin{tabular}{lll}
\hline \multicolumn{1}{l}{ Alternativas } & Frecuencia & Porcentaje \\
\hline Alta $(>0.08$ usd/litro) & 36 & $10 \%$ \\
$\begin{array}{l}\text { Media } \\
\text { usd/litro })\end{array} \quad(0.04-0.08$ & 192 & $54 \%$ \\
Baja $(<0.04$ usd/litro) & 128 & $36 \%$ \\
TOTAL & 356 & $100 \%$ \\
\hline
\end{tabular}

\section{Fuente: Los autores}

El 54\% de los ganaderos dicen recibir una rentabilidad "media" por la actividad lechera, el $36 \%$ mencionan que su rentabilidad producto de la actividad de producir leche es "baja", tan solo el 10\% considera que percibe una rentabilidad alta al producir leche.

\section{Encuesta analista de laboratorio}

La siguiente etapa que compone de forma significativa este trabajo es como las empresas procesadoras de lácteos presentes en el sector de Pastocalle perciben, califican y procesan la leche que llega a sus plantas, desde los pequeños productores. En el sector existen dos industrias importantes dedicadas al procesamiento de leche y sus derivados, las empresas en mención son Parmalat y Alpina, ambas industrias cumplen con certificaciones nacionales e internacionales de calidad, higiene, etc. Además cumplen con las normativas y leyes ecuatorianas, por lo tanto, se han aplicado un conjunto de preguntas a representantes de estas empresas, específicamente a los analistas de laboratorio, quienes están en contacto con el producto que ingresa a sus plantas de producción. Además que ellos aportan información real con datos específicos de normas de calidad, aplicadas en sus empresas y que influyen directamente en el pago por el producto que reciben en sus instalaciones. 
Se aplican un conjunto de 10 preguntas que se resumen a continuación, en la siguiente tabla se indican por lo tanto las interrogantes planteadas y la información proporcionada por los analistas de laboratorio de Parmalat y Alpina.

Tabla 10. Encuesta a analistas de laboratorio.

\begin{tabular}{|c|c|c|c|}
\hline $\mathbf{N}^{\circ}$ & Pregunta & Parmalat & Alpina \\
\hline 1 & $\begin{array}{l}\text { ¿Existe en } r \text { su } \\
\text { empresa política } \\
\text { de precios por } \\
\text { calidad de la } \\
\text { leche? }\end{array}$ & $\begin{array}{l}\text { Parmalat aplica Políticas de } \\
\text { Pago por calidad de leche } \\
\text { basados en análisis físico- } \\
\text { químicos y microbiológicos } \\
\text { y aplicados a las normativas } \\
\text { de la Legislación } \\
\text { Ecuatoriana respectiva que } \\
\text { está vigente. }\end{array}$ & $\begin{array}{l}\text { Alpina tiene Políticas de Pago } \\
\text { por calidad de leche que } \\
\text { cumple con la Legislación } \\
\text { Ecuatoriana actual. }\end{array}$ \\
\hline 2 & $\begin{array}{l}\text { ¿Cuál de los } \\
\text { indicadores es el } \\
\text { más determinante } \\
\text { para evaluar la } \\
\text { calidad de la } \\
\text { leche? }\end{array}$ & $\begin{array}{l}\text { La acidez y presencia de } \\
\text { antibióticos dan los } \\
\text { indicadores más } \\
\text { determinantes de calidad de } \\
\text { leche. Según la Norma NTE } \\
\text { INEN 13: Acidez titulable } \\
\text { debe estar entre 0,13 y 0,16 } \\
\text { (\%m/m). Antibióticos: La } \\
\text { NTE INEN 9:2008 indica } 5 \\
\text { ug/L máx. de Beta- } \\
\text { Lactámicos; 100 ug/L } \\
\text { máx. de Tetraciclínicos y } \\
\text { Sulfas. }\end{array}$ & $\begin{array}{l}\text { Presencia de agua adicionada } \\
\text { (Se } \\
\text { acepta NTE INEN } 15 \text { : } \\
\text { Crioscopía: -0,536 }{ }^{\circ} \mathrm{C} \text { a } \\
0,512^{\circ} \mathrm{C} \text { ). La presencia de } \\
\text { antibióticos y acidez son los } \\
\text { indicadores básicos más } \\
\text { tomados en cuenta para } \\
\text { evaluar la calidad de la leche } \\
\text { que ingresa a la Planta. Según } \\
\text { NTE INEN 9: 2008: Para } \\
\text { calidad higiénica TRAM de } 2 \\
\text { a } 5 \text { horas; para calidad } \\
\text { sanitaria } 5 \times 10^{5} \text { UFC/cm }{ }^{3}\end{array}$ \\
\hline 3 & $\begin{array}{lr}\text { ¿Califican a los } \\
\text { ganaderos } & \text { para } \\
\text { que } & \text { sean } \\
\text { proveedores } & \text { de } \\
\text { leche? } & \end{array}$ & $\begin{array}{l}\text { Los proveedores se } \\
\text { califican en base a la } \\
\text { calidad y volumen de leche. }\end{array}$ & $\begin{array}{l}\text { Los proveedores } \\
\text { seleccionan y califican } \\
\text { previamente en base a los } \\
\text { parámetros de calidad y } \\
\text { cantidad de leche que son } \\
\text { capaces de entregar. }\end{array}$ \\
\hline 4 & $\begin{array}{l}\text { ¿Los ganaderos } \\
\text { mantienen la }\end{array}$ & $\begin{array}{l}\text { Los proveedores mantienen } \\
\text { su nivel de calidad de leche }\end{array}$ & $\begin{array}{l}\text { El nivel de calidad de leche en } \\
\text { los ganaderos es fluctuante }\end{array}$ \\
\hline
\end{tabular}




\begin{tabular}{|c|c|c|c|}
\hline & $\begin{array}{lll}\text { calidad } & \text { de } & \text { la } \\
\text { leche? } & & \\
\end{array}$ & $\begin{array}{l}\text { en } 80 \% \text { aproximadamente, } \\
\text { existen fluctuaciones que } \\
\text { dependen de varios } \\
\text { factores. }\end{array}$ & $\begin{array}{l}\text { que dependen de varios } \\
\text { factores como estacionales, de } \\
\text { higiene, transporte, manejo, } \\
\text { etc. }\end{array}$ \\
\hline 5 & $\begin{array}{l}\text { ¿Con qué factores } \\
\text { se } \\
\text { relaciona la } \\
\text { calidad de la } \\
\text { leche? }\end{array}$ & $\begin{array}{l}\text { Con la higiene del ordeño, } \\
\text { el manejo y transporte de la } \\
\text { leche, enfriamiento entre } \\
\text { otros. Revisar NTE-INEN } \\
9: 2008 \text { para verificar } \\
\text { requisitos de calidad. }\end{array}$ & $\begin{array}{l}\text { Con las prácticas y } \\
\text { metodología } \\
\text { de ordeño, manipulación, } \\
\text { conservación y transporte de } \\
\text { la leche. }\end{array}$ \\
\hline 6 & $\begin{array}{l}\text { ¿Qué porcentaje } \\
\text { de leche recibida } \\
\text { viene previamente } \\
\text { Refrigerada? }\end{array}$ & $\begin{array}{l}\text { El 52\% aproximadamente } \\
\text { de la } \\
\text { leche ingresa a la Planta } \\
\text { previamente refrigerada por } \\
\text { parte de los proveedores. El } \\
48 \% \text { restante no viene } \\
\text { refrigerada con los riesgos } \\
\text { de calidad inherentes. }\end{array}$ & $\begin{array}{l}\text { El } 80 \% \text { aproximadamente de } \\
\text { la leche ingresa a la Planta } \\
\text { previamente refrigerada por } \\
\text { parte de los proveedores. }\end{array}$ \\
\hline 7 & $\begin{array}{l}\text { ¿Cuál es la causa } \\
\text { más frecuente por } \\
\text { la que se rechaza } \\
\text { la leche? }\end{array}$ & $\begin{array}{l}\text { Por acidez y presencia de } \\
\text { antibióticos se rechaza con } \\
\text { mayor frecuencia leche de } \\
\text { mala calidad. }\end{array}$ & $\begin{array}{l}\text { Por alta acidez, pésima } \\
\text { higiene y presencia de } \\
\text { antibióticos. }\end{array}$ \\
\hline 8 & $\begin{array}{l}\text { ¿Se evidencia en } \\
\text { la calidad de leche } \\
\text { que los ganaderos } \\
\text { aplican BPO’s } \\
\text { (Buenas Prácticas } \\
\text { de Ordeño)? }\end{array}$ & $\begin{array}{l}\text { No se evidencia en la } \\
\text { mayoría de casos. Cuando } \\
\text { los ganaderos aplican } \\
\text { BPO's la calidad de leche } \\
\text { generalmente es buena. } \\
\text { Cuando no se aplican la } \\
\text { calidad se ve comprometida } \\
\text { provocando su rechazo. }\end{array}$ & $\begin{array}{l}\text { La no aplicación de Buenas } \\
\text { Prácticas de Ordeño se } \\
\text { evidencia con leche de mala } \\
\text { calidad (alto contenido } \\
\text { bacteriano) que es causal para } \\
\text { rechazo inmediato. La } \\
\text { aplicación de BPO's garantiza } \\
\text { leche de buena calidad que } \\
\text { incluso gana incremento de } \\
\text { precio. }\end{array}$ \\
\hline 9 & $\begin{array}{l}\text { ¿La leche de mala } \\
\text { calidad afecta la } \\
\text { rentabilidad de los } \\
\text { ganaderos? }\end{array}$ & $\begin{array}{l}\text { La leche de mala calidad se } \\
\text { rechaza de inmediato sin } \\
\text { ninguna indemnización al } \\
\text { ganadero, lo cual genera }\end{array}$ & $\begin{array}{l}\text { La leche de mala calidad se } \\
\text { rechaza y en casos específicos } \\
\text { se retiene para entregar a la } \\
\text { autoridad competente para su }\end{array}$ \\
\hline
\end{tabular}




\begin{tabular}{|l|l|l|l|l|}
\hline & & $\begin{array}{l}\text { cuantiosos descuentos en } \\
\text { las }\end{array}$ & $\begin{array}{l}\text { disposición final. No hay } \\
\text { ninguna indemnización al } \\
\text { ganadero lo que constituye } \\
\text { planillas de pago yórdida económica para él y } \\
\text { liquidación quincenal o o } \\
\text { mensual afectando sus } \\
\text { ingresos y rentabilidad. } \\
\text { riesgo de retirarlo como } \\
\text { proveedor si es reiterativo y el } \\
\text { caso lo amerita. }\end{array}$ \\
\hline $\mathbf{1 0}$ & $\begin{array}{l}\text { ¿Cuáles son las } \\
\text { principales } \\
\text { enfermedades del } \\
\text { ganado } \\
\text { afectan la calidad } \\
\text { de la leche? }\end{array}$ & $\begin{array}{l}\text { Una de las principales } \\
\text { enfermedades que afectan } \\
\text { la calidad de la leche es la } \\
\text { mastitis. La Norma NTE } \\
\text { INEN 9:2008 indica valores } \\
\text { permisibles de RCS. } \\
\text { (750000 máx). }\end{array}$ & $\begin{array}{l}\text { Se ha detectado que la mastitis } \\
\text { es una de las enfermedades } \\
\text { más comunes que afectan la } \\
\text { calidad de la leche de los } \\
\text { ganaderos proveedores de } \\
\text { Alpina. }\end{array}$ \\
\hline
\end{tabular}

\section{Fuente: Los autores}

Finalmente se presenta una tabla de resumen que incluye la interpretación o análisis lo mencionado por los analistas de laboratorio en cada pregunta.

Tabla 11. Análisis de resultados encuenta a analistas de laboratorio

\begin{tabular}{|l|l|}
\hline $\mathbf{N}^{\circ}$ & Interpretación/ análisis \\
\hline $\mathbf{1}$ & $\begin{array}{l}\text { Las } 2 \text { empresas procesadoras principales de la zona aplican Políticas de pago por } \\
\text { calidad del producto y cumplen la Legislación Ecuatoriana correspondiente. }\end{array}$ \\
\hline $\mathbf{2}$ & $\begin{array}{l}\text { Los indicadores más determinantes para evaluar la calidad de la leche para las } \\
\text { Plantas entrevistadas son la acidez y presencia de antibióticos. Alpina además } \\
\text { pone énfasis en el contenido de agua adicionada (NTE INEN 15: Crioscopía: - } \\
\left.\text { 0,536 }{ }^{\circ} \mathrm{C} \text { a }-0,512^{\circ} \mathrm{C}\right) \text {. Se hace referencia a las normas INEN y valores } \\
\text { permisibles: NTE INEN 13: Acidez titulable entre 0,13 y 0,16 (\%m/m). } \\
\text { Antibióticos: NTE INEN 9:2008: 5 ug/L máx. de Beta-Lactámicos; 100 ug/L máx. } \\
\text { de Tetraciclínicos y Sulfas. }\end{array}$ \\
\hline $\mathbf{3}$ & $\begin{array}{l}\text { Las Plantas califican a los ganaderos para que sean proveedores por la calidad y } \\
\text { cantidad de leche que pueden proveer. }\end{array}$ \\
\hline $\mathbf{4}$ & $\begin{array}{l}\text { Los ganaderos no mantienen constante la calidad del producto que entregan } \\
\text { debido a varios factores que pueden ser estacionales, higiénicos, transporte, etc. }\end{array}$ \\
\hline $\mathbf{5}$ & $\begin{array}{l}\text { Los factores más relevantes relacionados con la calidad de leche son la } \\
\text { metodología de ordeño (BPO’s), el manejo, enfriamiento y transporte del }\end{array}$ \\
\hline
\end{tabular}




\begin{tabular}{|l|l|}
\hline & $\begin{array}{l}\text { producto. Se sugiere revisar NTE-INEN 9:2008 para verificar requisitos de } \\
\text { calidad. }\end{array}$ \\
\hline $\mathbf{6}$ & $\begin{array}{l}\text { En promedio las plantas reciben leche previamente refrigerada en un 66\%. El } \\
\text { volumen restante ingresa sin refrigeración previa, esto resta calidad al producto y } \\
\text { pone en riesgo al resto de volumen recepcionado. }\end{array}$ \\
\hline $\mathbf{7}$ & $\begin{array}{l}\text { Las causas más frecuente por la que se rechaza leche en las plantas procesadoras } \\
\text { entrevistadas son por alta acidez, presencia de antibióticos y pésima higiene. }\end{array}$ \\
\hline $\mathbf{8}$ & $\begin{array}{l}\text { Las plantas procesadoras de leche no evidencian la aplicación de BPO’s en la } \\
\text { mayoría de los ganaderos, lo cual se manifiesta con leche producida de mala } \\
\text { calidad (falta de higiene, alto contenido bacteriano, baja reductasa), que provoca } \\
\text { rechazo inmediato. }\end{array}$ \\
\hline $\mathbf{9}$ & $\begin{array}{l}\text { La leche de mala calidad si afecta negativamente al bolsillo del productor. Esta es } \\
\text { rechazada, no se da ninguna indemnización, lo cual afecta directamente a los } \\
\text { ingresos y rentabilidad de los ganaderos. }\end{array}$ \\
\hline $\mathbf{1 0}$ & $\begin{array}{l}\text { La enfermedad más frecuente que afecta la calidad de leche de los proveedores es } \\
\text { la mastitis, para las 2 empresas entrevistadas. Se indica además que la Norma } \\
\text { NTE INEN 9:2008 muestra valores permisibles de RCS. (750000 máx). }\end{array}$ \\
\hline
\end{tabular}

\section{Fuente: Los autores}

\section{Discusión}

Las empresas procesadoras de lácteos buscan y prefieren leche de excelente calidad, misma que tiene un precio alto por sus características físico químicas que cumplen y superan las normas de calidad exigidas por la autoridad correspondiente, lo que permite que el producto final sea totalmente saludable, que los procesos sean eficientes y no se dañen los equipos. Adicional a estas ventajas la leche de excelente calidad genera mayores ingresos y rentabilidad a los productores. La leche de buena calidad es buscada por las plantas procesadoras, pero es preferible que la leche sea de excelente calidad para obtener un mayor beneficio mutuo tanto para el productor como para el empresario que se dedica a procesarla.

En este análisis hay que tomar en cuenta las valoraciones mencionados en al marco teórico que nos permiten pasar de lo cualitativo a lo cuantitativo, esto es, según valoraciones mínimas promedio del MAGAP la rentabilidad se considera alta cuando su valor porcentual supera el $22 \%$ (mayor a $\$ 0,08 /$ litro de leche), media cuando se encuentra desde el $11 \%$ hasta el $22 \%$ (de $\$ 0,04 /$ litro a $\$ 0,08 /$ litro de leche) y baja cuando es menor del $11 \%$ (menor a $0,04 /$ litro de leche). 
Con una producción tecnificada de leche la calidad y cantidad se incrementa y consecuentemente los ingresos mejoran y suben significativamente logrando alta rentabilidad, convirtiéndose en un negocio atractivo y lucrativo. Las prácticas de producción de leche tradicionales restan eficiencia y hacen que el esfuerzo de producirla no sea compensado, esto desmotiva al productor que tiende cada vez más a migrar a otras actividades no agrícolas e incluso a migrar a la ciudad a buscar mejores ingresos.

\section{Conclusiones.}

- La calidad de leche ha influido de manera importante y directa en la rentabilidad de los ganaderos de la parroquia rural de Pastocalle provincia de Cotopaxi. Existe una relación directamente proporcional entre la calidad y rentabilidad, a mayor calidad, mayor rentabilidad y al contrario. Leche de excelente calidad alcanza precios altos, leche de buena calidad precios competitivos y leche de mala calidad se rechaza sin indemnización alguna al productor.

- Los principales tipos de problemas que afectan la rentabilidad de la leche son de calidad, la leche es rechazada especialmente por alta acidez, alto contenido bacteriano, mastitis, presencia de antibióticos y agua.

- Para mejorar la calidad de la leche existen algunas alternativas, entre las cuales, las más viables son la aplicación de Buenas Prácticas de Ordeño (BPO’s) acompañadas de adecuada capacitación.

- Para garantizar el almacenamiento y conservación de la leche lo ideal será la construcción de un Centro de Acopio y enfriamiento técnicamente diseñado, lo que permitirá obtener mayor rentabilidad por venta de un producto de excelente calidad mejorando el nivel de vida de los ganaderos.

\section{Referencias bibliográficas.}

Amiot, J. (1991). Ciencia y Tecnología de la Leche. Zaragoza, España: Acribia. S.A., p.120-124.

Balarezo Cisneros E.D. (2011). Implementación de un diseño de pago por calidad de leche en la Asunción San Francisco de Línea Roja, cantón Montufar (tesis de ingeniería). ESPE, Sangolquí, Ecuador.

Blowey R.W., Collis K. (1992). Efecto de la desinfección de los pezones en el pre ordeño y su incidencia en la mastitis, conteo total bacterial, conteo total de células en la producción de tres rebaños lecheros. Historial veterinario:130,175-178.

Chiavenato, I. (2008). Administración de Recursos Humanos. Quinta Edición. Santa Fé de Bogotá, Colombia: McGrawn. 
García, N. B. y N.J. Requelme (2011). Buenas prácticas de ordeño y la calidad higiénica de la leche en el Ecuador. La Granja, 14(2): 45-57

Luquet, F. (1993). Leche y Productos Lácteos. Vol.2. Zaragoza, España: Acribia.

Lituma Aguirre S.J. (2011). Comercialización de leche Bovina (tesis de ingeniería). Universidad de Cuenca. Cuenca, Ecuador.

Martínez De Ita, M.E. (2007). El Concepto de Productividad en el Análisis Económico. Red de Estudios de la Economía Mundial. México.

Philpot WN, S Nickerson (1993). Mastitis: El contraataque. Surge International Babson Bros Ed., Ill., USA.

Piñeros G. (2005). La Calidad como factor de Competitividad en la Cadena Láctea. Caso: Cuenca Lechera del Alto Chicamocha (tesis de ingeniería). Universidad Nacional de Colombia. Boyacá, Colombia.

Tamayo, C. (2012). Plan de Promoción y Difusión Turística para la Parroquia San Juan de Pastocalle, ubicado en el Cantón Latacunga, provincia de Cotopaxi (tesis de ingeniería). UTC, Latacunga, Ecuador.

Veisseyre, R. (1980). Lactología Técnica Composición, Recogida, Tratamiento y Transformación de Leche. Zaragoza, España: Acribia.

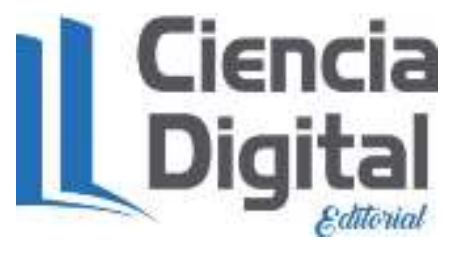




\section{PARA CITAR EL ARTÍCULO INDEXADO.}

Pallango E., Moreno M., Noguera A., Moreno F. \& Bonilla S. (2019). Análisis de la Calidad de leche producida por ganaderos rurales en la parroquia Pastocalle Cotopaxi y su influencia en la economía del sector. Revista electrónica Ciencia Digital 3(2), 529-547. Recuperado desde:

http://cienciadigital.org/revistacienciadigital2/index.php/CienciaDigital/article/view/450/1030

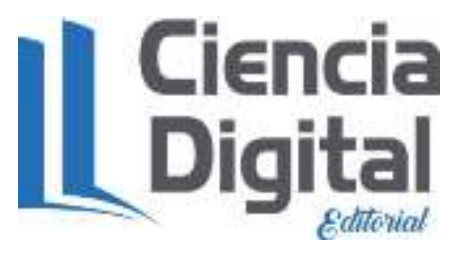

El artículo que se publica es de exclusiva responsabilidad de los autores y no necesariamente reflejan el pensamiento de la Revista Ciencia Digital.

El artículo queda en propiedad de la revista y, por tanto, su publicación parcial y/o total en otro medio tiene que ser autorizado por el director de la Revista Ciencia Digital.
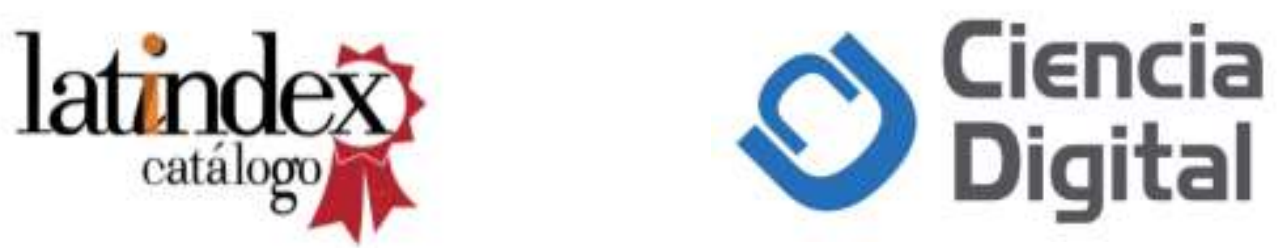